\title{
Research on Pitch Motion mode of SWATH based on System Identification
}

\author{
Zhaozhao MA, Songlin YANG, Shasha GAO, Zhanyuan CHENG, Baojiang WANG, Di ZHANG
}

\begin{abstract}
In this paper, a series of static water pitching attenuation tests were carried out on a small swath unmanned underwater SWATH-USV under different draft and different initial pitch angles. By changing the composition of the restoring moment and damping torque, 9 mathematical models of the system identification were established. By changing the composition of the restoring moment and damping moment, a systematic identification mathematical model for 9 modes of pitch attenuation motion was established. Based on the system identification theory and genetic algorithm, the system identification software was written in $\mathrm{C \#}$ language. The experimental data of the unmanned craft were identified and analyzed, and a good mathematical model of the longitudinal pitch motion was obtained by identification and calculation, and the changes of the parameters of the identification parameters under different water and tilt angles are compared. The variation of each identification parameter at different draught and tilt angles was also compared. The relative error between the software forecast value and the test value shows that the prediction value is in good agreement with the test value, which proves the reliability of the system identification software, and can predict the future navigation and motion posture of the unmanned craft.
\end{abstract}

Index Terms - SWATH-USV; pitch attenuation test; system identification; pitch motion mode.

\section{INTRODUCTION}

The SWATH ship [1] consists of three parts: deep underwater double submerged body, small water plane double pillar and spacious upper hull. Its characteristic is that the waterline surface is much smaller than the catamaran and is less disturbed by the wave, so it has excellent sea keeping ability and can perform offshore operations smoothly. According to the motion characteristics of the SWATH ship form, Ma Jianwen [2] based on the MMG three degrees of freedom model, and has incorporated the coupled longitudinal sway and yaw. The five degrees of freedom motion mathematical model of the SWATH were established by swaying, surging, rolling, pitching, yawing. Based on this application model, the real ship mathematical model of the SWATH is established, and the mathematical model is solved by differential solution. The cycle motion rotation and $\mathrm{Z}$ shape motion of the SWATH are simulated and the qualitative analysis is carried out. In the process of semi-submersible unmanned yacht, Jin Bo [3] has a great influence on the

Zhaozhao MA, Songlin YANG, Shasha GAO, Zhanyuan CHENG, Baojiang WANG, Di ZHANG, School of Naval Architecture \& Ocean Engineering, Jiangsu University of Science and Technology, Zhenjiang, Jiangsu, China external environment of the yaw and roll, which affects the effectiveness of the motion control system. The method of time series analysis and Grey prediction is used to study the motion attitude prediction method. The AR model and GM $(1,1)$ model was established based on the initial and longitudinal data of semi-submersible unmanned craft in general working conditions, and the real-time prediction simulation and comparison were carried out. Li Jun [4] proposed a multi-objective system identification method for surface unmanned craft, and verified the correctness of the method through the model test and calculation analysis. The loss functions of roll motion, roll motion and control motion are established by the error functions of rolling angular velocity, pitch angle velocity, lateral velocity and rotation angle velocity respectively. The evaluation function of mufti target identification optimization problem of unmanned yacht is constructed by subdivision method, and the mufti target identification problem of unmanned yacht is transformed into an evaluation function. Finally, a genetic algorithm is used to solve the optimal solution.

In this paper, the model of hydro static pitching motion of a SWATH-USV model was tested and analyzed. A mathematical model and method of system identification based on genetic algorithm [5] were established. The identification software was developed and the identification analysis of the longitudinal motion was carried out. The identification and analysis of the longitudinal rolling test data were carried out by the identification program. The relative error between the measured value and the predicted value is small, and the fitting degree is good, which proves the reliability of the system identification method.

\section{PITTING TEST OF HYDRO STATIC WATER}

\section{A. Test Model}

An SWATH-USV model is selected in this pitch test. Its main scale principal dimension is shown in table 1.1:

Table 1 Main parameters of SWATH-USV

\begin{tabular}{|c|c|c|c|c|c|c|c|}
\hline $\begin{array}{l}\text { principal } \\
\text { dimension }\end{array}$ & Symbol & $\begin{array}{l}\text { numerical } \\
\text { value }\end{array}$ & unit & $\begin{array}{l}\text { principal } \\
\text { dimension }\end{array}$ & Symbol & $\begin{array}{l}\text { numerical } \\
\text { value }\end{array}$ & unit \\
\hline Skipper & $L$ & 1.26 & $\mathrm{~m}$ & & & & \\
\hline $\begin{array}{l}\text { Yacht } \\
\text { width }\end{array}$ & B & 0.6 & $\mathrm{~m}$ & Design speed & V & 5 & $\mathrm{kn}$ \\
\hline $\begin{array}{l}\text { Type } \\
\text { depth }\end{array}$ & $D$ & 0.37 & $\mathrm{~m}$ & $\begin{array}{l}\text { Space } \\
\text { between } \\
\text { pieces }\end{array}$ & $c_{0}$ & 0.54 & $\mathrm{~m}$ \\
\hline $\begin{array}{l}\text { Design } \\
\text { draft }\end{array}$ & $T$ & 0.154 & $\mathrm{~m}$ & $\begin{array}{l}\text { Length of } \\
\text { submersible } \\
\text { body }\end{array}$ & $L$ & 1.28 & $\mathrm{~m}$ \\
\hline $\begin{array}{l}\text { Design } \\
\text { drainage }\end{array}$ & $\Delta$ & 30 & $\mathrm{~kg}$ & $\begin{array}{l}\text { Dive } \\
\text { diameter }\end{array}$ & $D_{1}^{h}$ & 0.128 & $\mathrm{~m}$ \\
\hline $\begin{array}{l}\text { Maximum } \\
\text { width of } \\
\text { pillar }\end{array}$ & $t_{s}$ & 0.538 & $\mathrm{~m}$ & Prop length & $L_{s}$ & 1.18 & $\mathrm{~m}$ \\
\hline
\end{tabular}

The completed model view is shown in Figure 1 : 


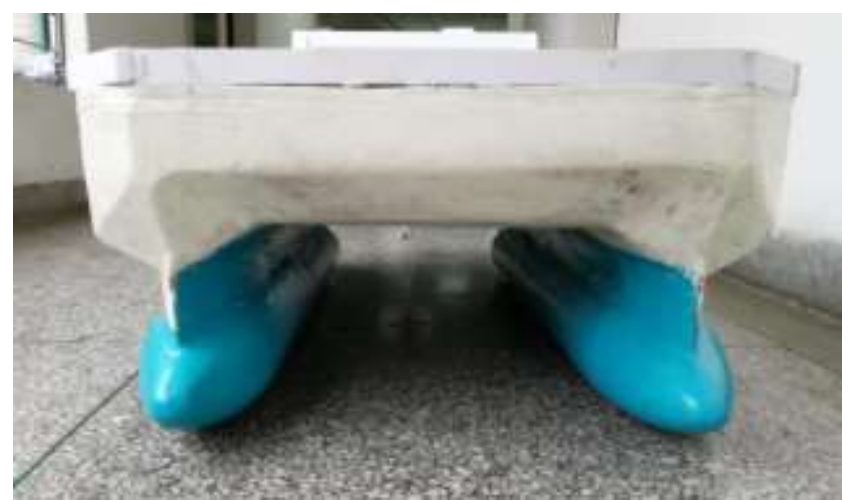

(a)

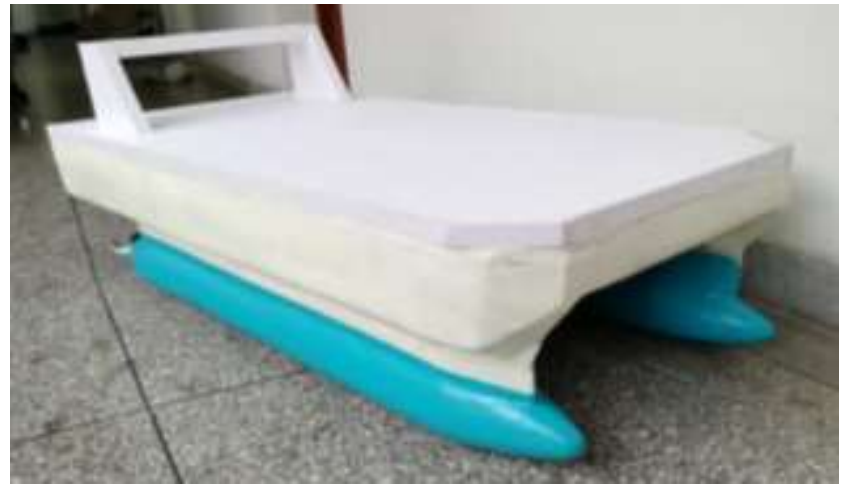

(b)

Figure 1 Front view of a two swath unmanned yacht model (a), Overall effect diagram (b)

\section{B. Test Steps of Pitching}

Due to the relationship between the test conditions, the pitch test cannot simulate the motion of the wave in the wave, and the swaying law of the ship model is determined mainly by measuring the swing angle of the ship model in the free decay process of the hydro static water. The test of the longitudinal pitching and rolling of the still water is carried out in this paper. The hydro static pitching test was conducted in a test pond.

(1) We prepared for trial the instrument including test model with length of 1.26 meter test ship model, the MTI-G inertial measuring instrument the ship's six degrees of freedom movement, the data transmission line, and the computer on the shore.

(2) in order to avoid the wall effect, the ship model is placed in the center of the pool, and the ship model is adjusted to float forward by loading weights, so that the draught is at the design water line.

(3) the MTI-G inertial measurement unit is placed horizontally on the center of gravity of the ship model and connected to the equipment with data lines.

(4) when the ship model is in the positive floating state, the data of the shore machine is observed to read the longitudinal angle of the ship model. By adjusting the horizontal position of the MTI-G, the initial pitch angle of the software is guaranteed to be between 0.1 degrees.

(5) manually give the ship model a required pitch angle, click record data, release the ship model at the same time, wait for the ship model to regain the positive floating state, stop data collection, and save the test data.

(6) repeating (4) process, changing the required pitch angle, and designing the initial pitch angle of the draft section in three groups, including: 3 degrees, 6 degrees, 9 degrees;
(7) by adding or reducing the load to carry out 1.1 and 0.9 times the design of the draft test, and adding two loading, repeat steps (3) - (5), the test process, as shown in Figure 1.2.

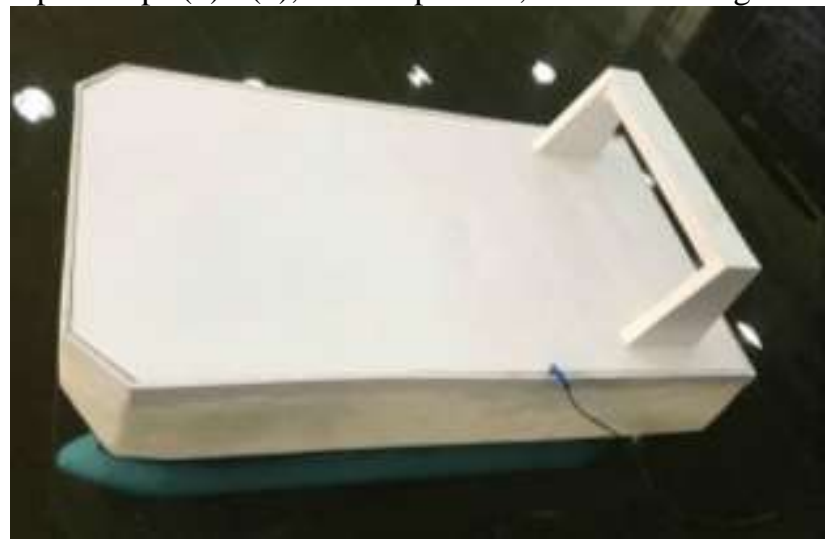

Figure 2 Hydro static pitching attenuation test of SWATH

\section{SYSTEM IDENTIFICATION EQUATION AND MATHEMATICAL MODEL}

System identification is a branch of modern control theory. System identification is a model [6] which is equivalent to the measured system in a set of given model classes on the basis of known or measured input and output data. The three elements of system identification are data, model class and equivalence criterion, in which data is the basis of identification, which refers to the input data and output data of the system process. The model class is the range of the identification of the model, referring to the set of known system process models, and the equivalence criterion is the target of identification and optimization. The essence of identification is to select a model from a group of known model classes according to certain criteria, so that it can best match the dynamic characteristics of the actual process [7].

The definition of Zadeh, such as [8-10], is that identification is based on input and output data, and determines a model that is equivalent to the measured system from a given set of model classes. Generally speaking, there are three elements in identification: data, models and criteria. Identification is to select a model that best fits the data in a set of model classes according to a criterion.

The following equation can be obtained from the equation of static water moment balance.

$$
\begin{aligned}
& \ddot{\psi}+2 N \dot{\psi} / I_{x x}^{\prime}+W|\dot{\psi}| \dot{\psi} / I_{x x}^{\prime} \\
& +x \dot{\psi}^{3} / I_{x x}^{\prime}+D h \psi / I_{x x}^{\prime}=0
\end{aligned}
$$

According to the characteristics of the ship type, the linear, the quadratic and the cubic combinations of the damping moment and restoration moment are transformed. A total of nine equations of the longitudinal pitch motion were established for the system identification and analysis to find the adjustment equation of the ship model in this paper.

Equation 1:

$$
\begin{aligned}
& \ddot{\psi}+2 N / I_{\mathrm{yy}}^{\prime} \dot{\psi}+W I_{\mathrm{yy}}^{\prime}|\dot{\psi}| \dot{\psi}+x / I_{\mathrm{yy}}^{\prime} \dot{\psi}^{3}+ \\
& C_{1} / I_{\mathrm{yy}}^{\prime} \psi^{3}+C_{2} / I_{\mathrm{yy}}^{\prime} \psi^{2}+C_{3} / I_{\mathrm{yy}}^{\prime} \psi=0
\end{aligned}
$$

Equation 2:

$$
\begin{aligned}
& \ddot{\psi}+2 N / I_{\mathrm{yy}}^{\prime} \dot{\psi}+W I_{\mathrm{yy}}^{\prime}|\dot{\psi}| \dot{\psi}+C_{1} / \\
& I_{\mathrm{yy}}^{\prime} \psi^{3}+C_{2} / I_{\mathrm{yy}}^{\prime} \psi^{2}+C_{3} / I_{\mathrm{yy}}^{\prime} \psi=0
\end{aligned}
$$


Equation 3:

$$
\begin{aligned}
& \ddot{\psi}+2 N / I_{\mathrm{yy}}^{\prime} \dot{\psi}+C_{1} / I_{\mathrm{yy}}^{\prime} \psi^{3} \\
& +C_{2} / I_{\mathrm{yy}}^{\prime} \psi^{2}+C_{3} / I_{\mathrm{yy}}^{\prime} \psi=0
\end{aligned}
$$

Equation 4:

$$
\begin{aligned}
& \ddot{\psi}+2 N / I_{y y}^{\prime} \dot{\psi}+W I_{y y}^{\prime}|\dot{\psi}| \dot{\psi}+x / \\
& I_{y y}^{\prime} \dot{\psi}^{3}+C_{2} / I_{y y}^{\prime} \psi^{2}+C_{3} / I_{y y}^{\prime} \psi=0
\end{aligned}
$$

Equation 5:

$$
\begin{aligned}
& \ddot{\psi}+2 N / I_{y y}^{\prime} \dot{\psi}+W I_{y y}^{\prime}|\dot{\psi}| \dot{\psi}+ \\
& C_{2} / I_{y y}^{\prime} \psi^{2}+C_{3} / I_{y y}^{\prime} \psi=0
\end{aligned}
$$

Equation 6:

$$
\ddot{\psi}+2 N / I_{\mathrm{yy}}^{\prime} \dot{\psi}+C_{2} / I_{\mathrm{yy}}^{\prime} \psi^{2}+C_{3} / I_{\mathrm{yy}}^{\prime} \psi=0
$$

Equation 7:

$$
\begin{aligned}
& \ddot{\psi}+2 N / I_{\mathrm{yy}}^{\prime} \dot{\psi}+W I_{\mathrm{yy}}^{\prime}|\dot{\psi}| \dot{\psi}+ \\
& x / I_{\mathrm{yy}}^{\prime} \dot{\psi}^{3}+C_{3} / I_{\mathrm{yy}}^{\prime} \psi=0
\end{aligned}
$$

Equation 8:

$$
\ddot{\psi}+2 N / I_{\text {yy }}^{\prime} \dot{\psi}+W / I_{\text {yy }}^{\prime}|\dot{\psi}| \dot{\psi}+C_{3} / I_{\text {yy }}^{\prime} \psi=0
$$

Equation 9:

$$
\ddot{\psi}+2 N / I_{\mathrm{yy}}^{\prime} \dot{\psi}+C_{3} / I_{\mathrm{yy}}^{\prime} \psi=0
$$

We selected the design variables as follows: $I_{\mathrm{yy}}^{\prime}, N, W, x, C_{1}, C_{2}, C_{3}$, the value range of design var iables is as follows:

$$
\begin{aligned}
& I_{\mathrm{yy}}^{\prime} \in[0,0.1], N \in[0,1], W \in[0,1], x \in[0,10], \\
& h \in[0,10], C_{1} \in[0,10], C_{2} \in[0,10], C_{3} \in[0,10]
\end{aligned}
$$

Of the above nine equations , $I_{\mathrm{yy}}^{\prime}$-the total inertia moment of hull longitudinal pitching ; $\psi$-pitch angle ; $\dot{\psi}$-pitch angle velocity ; $\ddot{\psi}$ —pitch acceleration ; $2 N$ - the linear damping moment coefficient, ; $W, x$-the nonlinear damping moment coefficient ; $C_{1}, C_{2}$-the nonlinear restoring moment coefficient ; $C_{3}$-the linear restoring moment coefficient 。

The above nine identifications models, by measuring the angle of the test $K$, have the error estimation criteria at $K+1$ time as follows:

$$
\varepsilon_{K+1}=\dot{\psi}_{K+1}^{\prime}-\dot{\psi}_{K+1}
$$

In the form: $\dot{\psi}_{K+1}$ - the measured value of the angular velocity of the $K+1$ moment; $\dot{\psi}_{K+1}^{\prime}$ - the value obtained from the identification result.

According to the error estimation criterion, the objective function of pitch identification model is established as follows:

$$
F(x)=\sqrt{1 / N \sum_{k=1}^{N}\left(\dot{\psi}_{K+1}^{\prime}-\dot{\psi}_{K+1}\right)^{2}}
$$

\section{A. Comparative analysis of test data}

In the test process, three tests are carried out for each initial pitch angle during the test, and the best data of the test data are selected as the effective data. Due to human measurement factors, there are some errors in the experiment. The initial angle of the longitudinal pitch is 3 degrees, and the draft of the draft is 0.9 times the design draft, the design draft, the 1.1 times the design of the draft, and the velocity attenuation of the pitch angle in the Figure 3, so the test data can be used. So the data of pitch test are available.

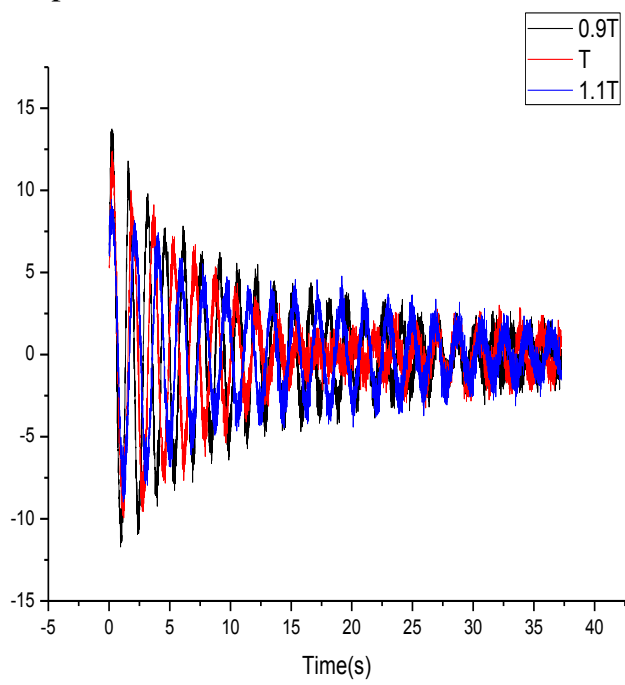

Figure 3 The curve of angular velocity at different initial draft angles of 3 degrees

As shown in Figure 3, when the three groups of water and initial angle of pitch are 3 degrees, with the increase of water, the peak value of the pitch angle decreases and the longitudinal rolling period increases. It shows that the higher the load is, the worse unfavorable the wave resistance performance is. The attenuation law of the red curve (design draft) appears in the abnormal state when the red curve (design draft) is at 15s. The reason may be the reflection of the two bodies on the waves, weakening the pitch motion. In addition, the longitudinal attenuation period of the ship model is longer than that of the general single ship, one is that the longitudinal roll motion is accompanied by the rolling movement in the process of longitudinal rolling, and the rolling period is close to the rolling period, and the "wagging" is formed, and the two is due to the layout factors and the position of the ballast placement. The center of gravity of the ship model is high, and it needs to be improved. Since the pitch motion was affected at $15 \mathrm{~s}$, only the test data of the first $15 \mathrm{~s}$ were taken for pitch identification.

\section{B. Analysis of Identification Results}

Genetic algorithms are selected to set the basic parameters as: optimization algebra 2000, population size 200, cross probability 0.8 , mutation probability 0.15 , genetic factor 0.05 , and evolutionary weight 0.9 .

The identification system of three different drafts and different initial pitch angles with nine different pitch mathematical models is identified and identified, as shown in Table 2:

\section{ANALYSES}


Research on Pitch Motion mode of SWATH based on System Identification

Table 2 Identifying the value of the objective function of a mathematical model

\begin{tabular}{|c|c|c|c|c|c|c|c|c|c|c|}
\hline $\begin{array}{l}\text { Objective } \\
\text { value }\end{array}$ & function & Equation 1 & Equation 2 & Equation 3 & Equation 4 & Equation 5 & Equation 6 & Equation 7 & Equation 8 & Equation 9 \\
\hline \multirow{3}{*}{$\begin{array}{l}\text { Initial } \\
\text { angle of } 3 \\
\text { degrees }\end{array}$} & $0.9 \mathrm{~T}$ & 0.023405752 & 0.0234057 & 0.023428109 & 0.023406 & 0.023405970 & 0.023428259 & 0.023407885 & 0.023407881 & 0.023429430 \\
\hline & $\mathrm{T}$ & 0.023476381 & 0.02347629 & 0.023476849 & 0.0234766 & 0.023477119 & 0.023477101 & 0.023484324 & 0.023484730 & 0.023484725 \\
\hline & $1.1 \mathrm{~T}$ & 0.059237538 & 0.05923563 & 0.059291416 & 0.0592373 & 0.059245461 & 0.059291401 & 0.059237292 & 0.059245535 & 0.059291473 \\
\hline \multirow{3}{*}{$\begin{array}{l}\text { Initial } \\
\text { angle of } 6 \\
\text { degrees }\end{array}$} & $0.9 \mathrm{~T}$ & 0.024820112 & 0.02481978 & 0.024884315 & 0.0248214 & 0.024821285 & 0.024821278 & 0.024823878 & 0.024823858 & 0.024823842 \\
\hline & $\mathrm{T}$ & 0.023195876 & 0.02319572 & 0.023195439 & 0.0231975 & 0.023197448 & 0.023197438 & 0.023204474 & 0.023222002 & 0.023204458 \\
\hline & $1.1 \mathrm{~T}$ & 0.0202619 & 0.02026185 & 0.020270943 & 0.0202627 & 0.020262725 & 0.020272272 & 0.020262657 & 0.020262722 & 0.020272257 \\
\hline \multirow{3}{*}{$\begin{array}{l}\text { Initial } \\
\text { angle of } 9 \\
\text { degrees }\end{array}$} & $0.9 \mathrm{~T}$ & 0.026101928 & 0.0261004 & 0.026100687 & 0.0261049 & 0.026104799 & 0.026104746 & 0.026105510 & 0.026105448 & 0.026105441 \\
\hline & $\mathrm{T}$ & 0.025670453 & 0.0256616 & 0.025662312 & 0.0256785 & 0.025678388 & 0.025836097 & 0.025686201 & 0.025686116 & 0.025686081 \\
\hline & $1.1 \mathrm{~T}$ & 0.023390004 & 0.02338618 & 0.023386278 & 0.0233979 & 0.023397692 & 0.023397671 & 0.023397712 & 0.023397661 & 0.023397652 \\
\hline
\end{tabular}

By comparing the objective function values of the above nine equations, it is found that the objective function value of the 3 initial longitudinal pitching angles and the 3 different drafts equation 2 is the least, indicating that the fitting effect of the equation 2 is the best. Taking the design of the draft angle of 6 degrees below the draft as an example, the identification equation is as follows:

$$
\begin{aligned}
& \ddot{\psi}+0.137953966 / I_{y y}^{\prime} \dot{\psi}+0.006320314 / \\
& I_{y y}^{\prime}|\dot{\psi}| \dot{\psi}+8.704769096 / I_{y y}^{\prime} \psi^{3}+ \\
& 1.744499553 / I_{y y}^{\prime} \psi^{2}+0.910961951 / \\
& I_{y y}^{\prime} \psi=0
\end{aligned}
$$

In order to analyze the error of the test value and the fitting value, the experimental values of the angular velocity of the design draft and the initial angle of 9 degrees are compared with the fitting values identified by formula 2 , as shown in Figure 4

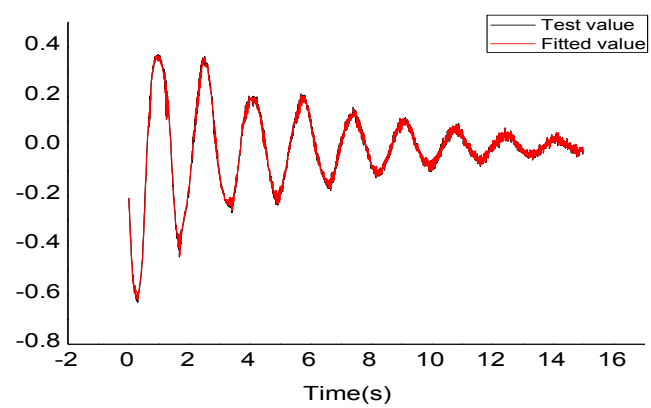

Figure 4 The curve of Test angular velocity and identification angle velocity fitting curve

Table 3 Error table of experimental and identification results

\begin{tabular}{llll}
\hline Time $(\mathrm{s})$ & Experimental angular velocity & Angular velocity identification & error \\
\hline 0.32 & -0.598542757 & -0.599854568 & $0.22 \%$ \\
0.33 & -0.597305415 & -0.586284718 & $1.85 \%$ \\
0.34 & -0.592448517 & -0.584074995 & $1.41 \%$ \\
0.35 & -0.580790576 & -0.578335304 & $0.42 \%$ \\
0.36 & -0.572090756 & -0.565955143 & $1.07 \%$ \\
0.37 & -0.570465969 & -0.556495185 & $2.45 \%$ \\
0.38 & -0.555617801 & -0.553977795 & $0.30 \%$ \\
0.39 & -0.543450262 & -0.538521542 & $0.91 \%$ \\
0.4 & -0.536940663 & -0.525712422 & $2.09 \%$ \\
0.41 & -0.517738224 & -0.518458466 & $0.14 \%$ \\
\hline
\end{tabular}

According to Figure 4, it can be seen that the fitting effect of test angular velocity and identification angular velocity is better. It can be seen from Table 3 that the error between the test angular velocity and the angular velocity is less than $3 \%$, indicating that the software is reliable and can predict the angular velocity at the next moment.

\section{Analysis of the Hydrodynamic Torque Coefficient of the Longitudinal Pitching}

Through the identification and calculation of the 9 groups of longitudinal test data, the total inertia moment of the hull $I_{\mathrm{yy}}$, the linear damping torque coefficient $N$, the nonlinear damping torque coefficient $W$ and $\mathrm{x}$, the linear recovery moment coefficient $\mathrm{C}_{3}$ and the nonlinear recovery moment coefficient $C_{1} 、 C_{2}$ are obtained. Among them, at different initial pitch angles, the hydrodynamic moment coefficient of the ship's pitch is measured with the draft curve shown in figure 3.3-3.5.
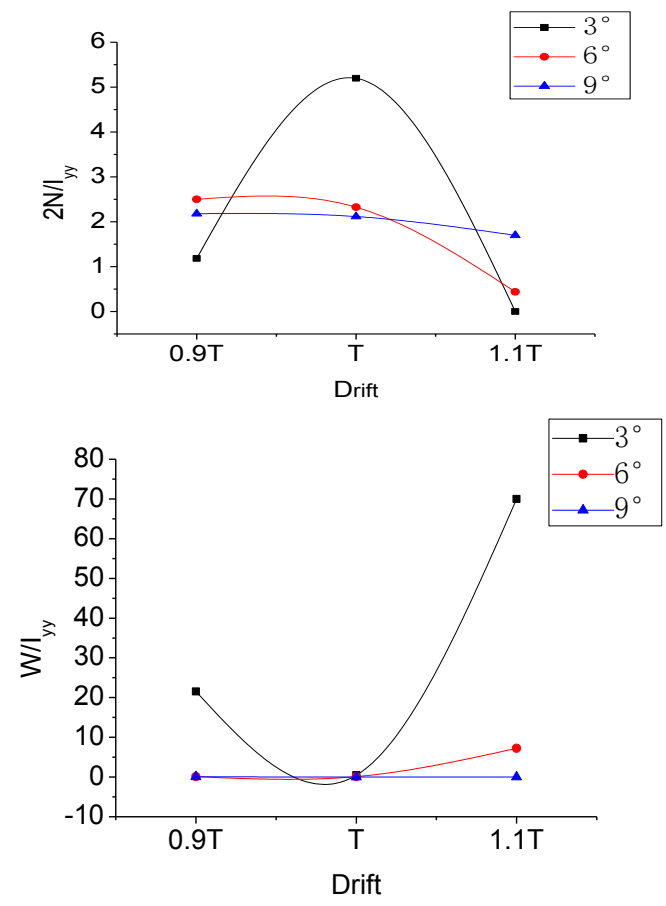

Figure 5 The curve of relative linear damping coefficient $N$ (left) and relative damping moment coefficient $W$ (right) vary with initial pitch angle and draft 

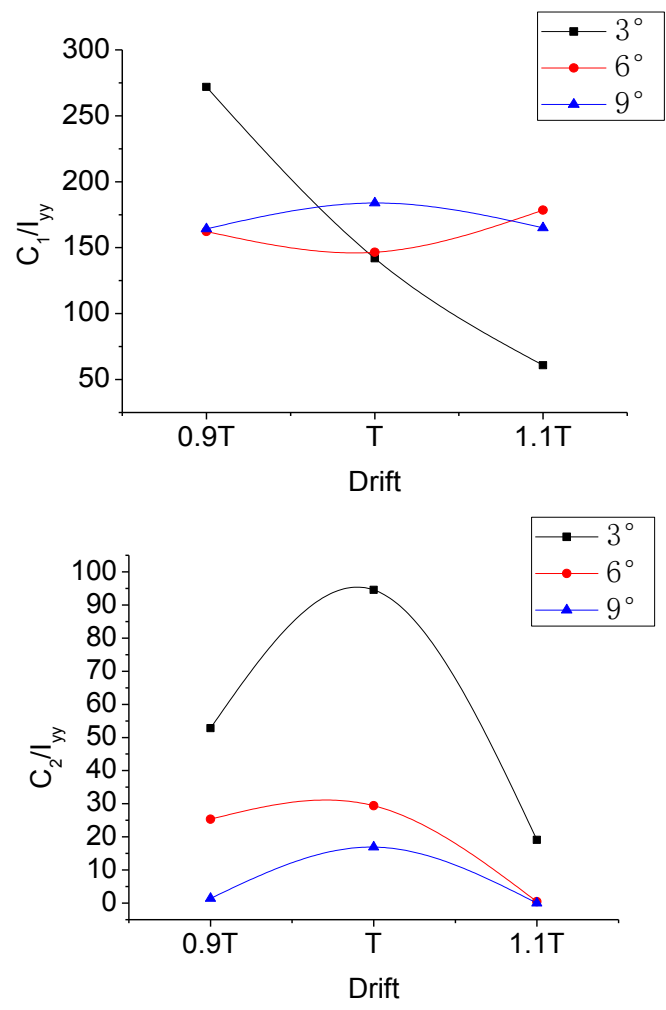

Figure 6 The curve of relative nonlinear restoring moment coefficients $C_{1}$ and $C_{2}$ vary with initial pitch angle and draft

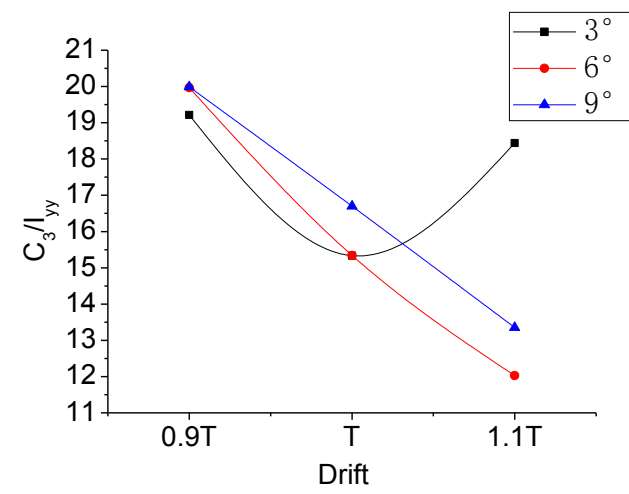

Figure 7 The curve of relative linear restoring moment coefficient varies with initial pitch angle and draft

It can be seen from Figure 5-7 that the values of the moment coefficients change with the change of draft and initial pitch angle. The relative linear damping torque coefficient $N$ decreases with the increase of the initial pitch angle. When the angle of the pitch is 3-6 degrees, the relative linear damping torque coefficient $N$ presents a tendency to increase first and then decrease, while the relative linear damping torque coefficient $N$ decreases when the pitch angle is 6-9 degrees. The damping torque is smaller, and the relative damping torque coefficient $W$ decreases with the increase of the initial pitch angle. When the angle of the pitch is 3 degree, the relative damping torque coefficient $W$ decreases first and then increases. While the pitch angle at 6-9 degrees, the trend of the damping moment is in the flat basically near zero, indicating that the damping torque does not exist at a large angle. The nonlinear recovery moment coefficient $C_{l}$ decreases with the increase of draft water at 3 degrees, and the change amplitude is slow between 6-9 degrees, and the relative nonlinear recovery moment coefficient $C_{2}$ increases with the increase of water, and decreases with the increase of the pitch angle. The relative linear recovery moment coefficient $C_{3}$ increases first and then decreases with the increase of the draft angle at 3 degrees, while the pitch angle at 6-9 degrees decreases with the increase of the draft.

\section{CONCLUSION}

In this paper, the model test and system identification method are used to study the damping motion mode of the hydro static roll in the swath unmanned yacht. Through the identification program calculation, a mathematical model of the static water longitudinal rolling is found that is the most suitable for the ship model in the 81 working conditions, which can accurately describe the process of the roll motion and give the exact value of the moment coefficient. The variation of each moment coefficient with the angle of draft and roll is found, and the reliability of the system identification software is verified. The research shows that the system identification software can predict the future navigation parameters and motion attitude of unmanned ships, which can provide a reference for further study of the longitudinal motion of SWATH USV.

\section{ACKNOWLEDGEMENT}

This project is funded by the following projects: The National Natural Science Foundation of China, the project approval number is 51379094

\section{REFERENCE}

[1] Fanjingfeng.xiao J] .. Journal of the Jiangsu University of Science And Technology(Natural Science Edition), 2000(4): 53-53

[2] Ma Jianwen, Zhang Anxi, Zhou Zhaoxin, et al. Modeling and Simulation of five degree of freedom motion for SWATH ship [J]. Chinese ship research, 2017, 12 (2): 133-136.

[3] Yu Jinbo, Hu Zhiqiang, Geng Ling Bo, Yang Yi. Motion prediction method for semi submersible unmanned vehicle [J]. computer simulation, 2018,35 (02): 251-256.

[4] Li Jun. Research on a motion pattern recognition system for surface unmanned craft [D]. Jiangsu University of Science and Technology, 2016

[5] She Minghong. Application and analysis of genetic algorithm in system identification [J]. Research results, 2016, 11

[6] Zhang Heng, Li Jide, Zhao Xiaodong. Solving nonlinear motion responses of ships based on system identification method [J]. Journal of Dalian Maritime University, 2008, 34 (4):67-71.

[7] Lei Jian. Algorithm and application of RBF neural network based on support vector machine [D]. Jiangxi University of Science and Technology, 2008.

[8] Zadeh L A. Form Circuit Theory to System Theory[J]. Proc. IRE, 1962, 59(5):856-865.

[9] D Dumitru,Numerical investigation of a two - degrees - of - freedom ship model for pitch -roll motion [ C ] ,IOP Conference Series:10.1088/1757-899X/145/8/082007,2016.

[10] Deleanu D. COMPARATIVE APPROXIMATE STUDIES ON THE SHIP'S ROLLING MOTION[J]. 2015, 1:29-36.

[11] Shao Kaiwen, Ma Yun Yi. Introduction to ship technology and design [M]. Beijing: National Defense Industry Press, 2005:44-58.

[12] Zaraphonitis G, Grigoropoulos G J, Damala D P, et al. Seakeeping Analysis of two Medium-speed Twin-hull Models[J]. Journal of Ship Production \& Design, 2018, 30(4):1-9.

[13] Taghva H R, Ghassemi H, Nowruzi H. Seakeeping Performance Estimation of the Container Ship under Irregular Wave Condition Using Artificial Neural Network[J]. 2018, 6(4):147-153.

[14] Monroy C, Seng S. Time-stepping schemes for seakeeping in OpenFOAM $[\mathrm{C}] / /$ International Workshop on Ship and Marine Hydrodynamics. 2017.

[15] Carli F P, Chen T, Ljung L. Maximum Entropy Kernels for System Identification[J]. IEEE Transactions on Automatic Control, 2017, 62(3):1471-1477. 
[16] Feldman M, Braun S. Nonlinear vibrating system identification via Hilbert decomposition[J]. Mechanical Systems \& Signal Processing, 2017, 84:65-96.

[17] Yu W, Tan J, Liu C K, et al. Preparing for the Unknown: Learning a Universal Policy with Online System Identification[J]. 2017.

[18] Li Y, Cui W G, Guo Y Z, et al. Time-Varying System Identification Using an Ultra-Orthogonal Forward Regression and Multiwavelet Basis Functions With Applications to EEG[J]. IEEE Trans Neural Netw Learn Syst, 2017, PP(99):1-13.

[19] Chen T. On kernel design for regularized LTI system identification[J]. Automatica A Journal of Ifac the International Federation of Automatic Control, 2017, 90:págs. 109-122.

[20] Li Y, Wang Y, Yang R, et al. A Soft Parameter Function Penalized Normalized Maximum Correntropy Criterion Algorithm for Sparse System Identification[J]. Entropy, 2017, 19(1).

[21] Batselier K, Chen Z, Wong N. A Tensor Network Kalman filter with an application in recursive MIMO Volterra system identification $2[\mathrm{~J}]$. Automatica, 2017, 84:17-25.

[22] Prando G, Chiuso A, Pillonetto G. Maximum Entropy vector kernels for MIMO system identification $乞[\mathrm{~J}]$. Automatica, 2017, 79:326-339.

[23] Stöckl A L, Kihlström K, Chandler S, et al. Comparative system identification of flower tracking performance in three hawkmoth species reveals adaptations for dim light vision.[J]. Philos Trans R Soc Lond B Biol Sci, 2017, 372(1717):20160078.

[24] Kramer O. Genetic Algorithm Essentials[M]. Springer International Publishing, 2017.

[25] Martínez-Cañada P, Morillas C, Plesser H E, et al. Genetic algorithm for optimization of models of the early stages in the visual system[J]. Neurocomputing, 2017, 250:101-108.

[26] Su Y, Chu X, Chen D, et al. A genetic algorithm for operation sequencing in CAPP using edge selection based encoding strategy[J]. Journal of Intelligent Manufacturing, 2017(9-10):1-20. 